\section{Vegetable and mineral}

\section{Paul Calvert}

ORGANIC polymers are soft and tough, glasses are hard and brittle. The high melting temperature of glasses has normally made them incompatible with polymers but recent work on 'sol-gel' glass preparation has allowed the synthesis of hybrids of polymers and glasses which have variously been called ormosils, ceramers and polycerams. So far most research on these materials has been of the "look what I've got" school. The burgeoning interest in these novel materials was reflected in the first symposium dedicated to them*. Much of the debate was focused on chemists' emerging ability to control the microstructures of the hybrid materials.

The sol-gel method for silica glass is based on the hydrolysis of silicon tetraethoxide in an acidic alcohol solution. The first product is a soft gel containing $10-\mathrm{nm}$ silica particles. As this gel is dried, it shrinks to form a porous, lowdensity silica matrix in which voids take up 50-99 per cent of the volume. Firing at $600{ }^{\circ} \mathrm{C}$ increases the density. Glass formed this way usually breaks up into small pieces as differential shrinkage generates high stresses during drying and densification. This is not a significant problem for thin films, and the only widespread application of sol-gel chemistry at present is for heat-reflective coatings on glass ${ }^{1}$. Work is continuing on large pieces such as mirrors and lenses. (The standard method is not restricted to silica gels but can be used to make more interesting films such as conductors, dielectrics and superconductors.)

One way of toughening the product is to incorporate flexible polymers. For example it is possible to impregnate the dried open gel with methacrylate monomer which is subsequently polymerized to form a composite of glass and polymer ${ }^{2}$. The close match between the refractive indices of the components makes this composite quite transparent. Alternatively, rubbery polymers can be impregnated with alkoxides which are then hydrolysed to form the glass component ${ }^{3}$.

Another approach is to bond the polymer covalently into the gelling silica. Wilkes and co-workers have used sol-gel reactions carried out in solutions containing dissolved polymers or oligomers which carry silane groups. These groups become incorporated into the forming silica, interlocking the two components 4 . And mixtures of metal alkoxides containing some polymerizable organic groups can be hydrolysed and the orga-

* Meeting of the American Chemical Society, New York, 26-30 August 1991. nic component then polymerized either thermally or photochemically ${ }^{5}$. These hybrids can be made dense and thick with no danger of cracking ${ }^{6}$.

Ellsworth and Novak $^{7}$ have recently described a combination of ring-opening metathesis polymerization with sol-gel formation which illustrates clearly the factors determining structure. Polymers can be made from cyclic alkene monomers combined with functional groups that can be used to tune the properties of the hybrid or can act, for example, as sensors or as optically active units. But, significantly, the authors also find that, by modifying the polymer and the conditions, it is possible to do the reaction as 'polymer-first', 'glass-first' or simultaneous processes.

The simultaneous method gives a very homogeneous material with a structure finer than is obtained using preformed polymer. It is preferable that the chemistry of polymerization and of gelation occurs distinctly, without any crossinfluences. This seems to be the case when ring-opening metathesis polymerization is used but is not always true, for instance, with free-radical polymerization or epoxy condensation.

There is a catch, which is that the products are dark brown. At the meeting, Novak mentioned, but held back from naming, a colourless alternative to the normal ruthenium catalyst.

I. A. David and G. W. Scherer (Du Pont) described making many polymersilica blends looking for a true molecular dispersion ${ }^{8}$. Gel formation from solutions containing poly(ethyloxazoline) forms homogenous hybrids wih no signs of phase separation. They looked at the reduction in brittleness of the hybrid with increasing polymer content.

As with most new materials, it is not obvious what these hybrids will be good for. The only application so far is in scratch-proof coatings for plastic lenses 5 . Of real potential interest are hybrids containing rhodamine laser dyes dissolved in the polymer fraction ${ }^{9}$. The solid composite replaces the stream of fluorescent dye solution that passes through the optical cavity of conventional dye lasers. The claim is that the dye lifetime is much improved. Other optical applications, including materials for electrochromic devices and for optical second-harmonic generation, are being explored.

A true materials scientist worries ab-

\title{
The torque of Snettisham
}

\author{
IMAGE \\ UNAVAILABLE \\ FOR COPYRIGHT \\ REASONS
}

SINCE 1948 a site at Snettisham in Norfolk, UK, has been yielding treasure from the last few centuries BC. Principal among the finds, discussed by I. M. Stead in the latest issue of Antiquity $(65,447-465 ; 1991)$, are magnificent gold torques (neck rings). The latest hoards were discovered last year, and Stead deals in detail with the curious British law of treasure trove. If an object was buried with the intention of retrieval, it is declared treasure trove, is seized by the Crown and the finder is rewarded. Otherwise, it belongs to the landowner. So had the latest hoard been part of an Iron Age treasury (in which case it would be treasure trove) or had it been left as a votive offering (in which case it would not)? A court plumped for the treasury explanation, but although Stead finds it the more satisfactory he argues that the law (which required the court to decide what was in the mind of a person burying treasure two thousand years ago) is inappropriate when applied to archaeological excavations.

Tim Lincoln 